\title{
Evaluation of modern equipment for automated control and maintenance systems for mine transport
}

\author{
Georgiy Vishniakov ${ }^{*}$,Evgeniy Pushkarev \\ ${ }^{1}$ Saint-Petersurg Mining University, 2, 21st lane, St. Petersburg, 199106, Russia. \\ ${ }^{2}$ Saint Petersburg State University of Architecture and Civil Engineering Sciences, 4, Vtoraya Krasnoarmeiskaya ul., St. Petersburg, \\ 190005, Russia.
}

\begin{abstract}
The article presents the results of an analytical study of the equipment of production facilities for automatic control and maintenance of mining equipment. The analysis of the needs of enterprises in parameter control systems and the actual availability of these systems is carried out. Based on the list of parameters, conclusions are drawn about the development of modern automated control systems. The list of parameters was divided into groups to simplify data processing, as well as to be able to draw conclusions about each specific group. The solution of the problem is presented, which allows one to optimize the operation of the equipment and to avoid the occurrence of critical situations as much as possible.
\end{abstract}

\section{Introduction}

The development of various automatic control systems for the mining transport complex is the most important direction of modernization. In particular, the main aspect is the modernization of various methods of unmanned excavation and transportation of minerals.

In the development of robotization there are the best conditions for increasing the productivity of mining complexes not only in terms of efficiency, but also in terms of production safety. In the future, unmanned robotic excavation and loading technologies will change the system of production organization. All these factors contribute to an increased interest in this topic.

The pace of development of the mining industry is constantly increasing. This contributes to the accelerated modernization of various equipment, without which effective work is simply impossible. Special attention is always given to motor transport, because it is one of the biggest parts of minerals transportations in the world [1,2]. Dump trucks showed the highest level of productivity and reliability because they are constantly modernizing and introducing the best and most modern equipment. A striking example of such equipment is the system of automatic control and maintenance. Various companies are trying to excel in the field of automated control, and in some cases, even switch to robotic control (CAT, Komatsu, BelAZ).

However, in addition to improving the technology, there is a procedure for expanding the scope of these technologies implementation in more composite conditions. In order to solve complex problems at largescale facilities, in particular in the quarries of the north, where mining, geological and climatic conditions are not

\footnotetext{
*Corresponding author: geroibeka@yandex.ru
}

suitable sometimes for the infrastructure needed by humans [3-7].

The efficiency of robotic technology development is achieved by introducing a huge number of changes to the standard methods of mining enterprises design: changing the parameters of quarry roads, expanding excavations, changing the mode and schemes of robot movement, the exclusion of specific elements that were necessary for safe human work. It leads to the modification of the main parts of the quarry (benches, sides, slopes). When compared with the current technologies of mining and transportation of minerals, robotic machines can provide an increase in the efficiency of mining operations, increase the productivity of machines and the safety of work by reducing downtime and other operations that waste time due to the human factor [8-12].

Active monitoring and timely maintenance of the machine which is comprised of a number of systems of different types and sensors are used for effective control. They provide various information about the operation of the dump truck in real time [13-18].

\section{Promising research}

Based on the analysis of data on experience in the development and the use of robotic technology, 3 assumptions can be identified:

1. When remote or robotic control equipment is installed on dump trucks, tire wear will increase, which will result in a negative economic effect. At the same time, at various mining enterprises, during the sequence of various types of practices, it was found that all dump trucks drove with constant overload, which also has a negative impact on tire wear. If remote/robotic control systems are used, there will be a need to install many 
additional sensors, including a dynamic load weight sensor, and the program will not allow the machine to be overloaded to avoid increased tire wear [19-22].

2. Good road conditions also play an important role in the successful use of automated dump truck control systems. Naturally, such road conditions are not cheap, but the effect of longer serviceability of various technical elements of the machine (tires, hydraulic system elements, running gear) will be clearly seen.

3. Most often at quarries with already operating fleet of dump trucks companies try to install exactly those systems of remote control and maintenance that will have the maximum operational economic effect, for example, the system of fuel control and the system of registration of truck trips. However, other important parameters can be neglected: the speed control system, sensors controlling oil in the engine, transmission and the tire pressure control system. The installation of more systems will allow the drawing of a conclusion about the inefficient use of certain aspects of the machine and possible economic losses. The reasons are the lack of removable parameters of control and maintenance systems [23-26].

Experience in using automated control systems at mining enterprises, in particular, automated control of dump trucks, shows that one of the most important factors in increasing the productivity of the transport process is to increase the speed of the dump truck due to the absence of a person in the process of transportation. In turn, changing the speed mode is possible due to:

- elimination of the human factor when operating the machine;

- removal of restrictions on the speed of movement, as a person is not in the immediate vicinity of the process.

On the basis of various studies of this research topic, the conclusions were made that the automated control allows saving up to $10 \%$ of diesel fuel (possible fuel theft is excluded, the drive under the control of a robot becomes smoother). The productivity increases by 12$13 \%$ by the volume of transportation and by $19-20 \%$ by the cargo turnover due to the process optimization and downtime reduction. Increase of the duration of effective equipment operation was demonstrated. Furthermore, systematic repair and maintenance of rolling stock provided increase of service life of components and units [27].

\section{Results and Discussion}

Analytical assessment of the technical level of the existing systems for monitoring technical parameters shows which factors are important for enterprises, what specific information enterprises receive or would like to receive. [28] A total of 4 groups of parameters were considered:

- Loading and Fuel Control System (LFCS);

- Internal combustion engine system (ICE);

- Electric traction drive control system (ETCS);

- Hydraulic system.
In each of these groups, the most important parameters were considered:

Loading and fuel control system parameters (LFCS):

- dynamic weight of the cargo being carried;

- fuel level in the tank;

- slope values (longitudinal and transverse);

- pressure in suspension cylinders;

- status of connected analog and digital sensors;

- elevation of platform;

- state of handbrake;

- direction of movement of the truck;

- data by trips and shifts;

- pressure and temperature in tires (if the system of pressure control in tires is connected);

- suspension and frame condition;

- driving quality;

- technological road condition.

- geo-position (location in space)

- total running hours

- idle running hours

- fuel purity (presence of impurities/liquids in the gas tank)

- possibility of remote control of the vehicle (remote start/lock the engine)

- fuel temperature;

- driver's required torque;

- remote accelerator pedal pressure.

ICE parameters:

- actual engine speed;

- actual torque;

- atmospheric pressure;

- injector injection pressure;

- intake manifold pressure;

- engine oil pressure;

- coolant pressure;

- crankcase gas pressure indicator;

- low oil level indicator;

- engine load;

- accelerator pedal pressure;

- battery voltage;

- fuel consumption;

- speed of power gain;

- intake manifold temperature;

- engine coolant temperature;

- WRT regulator switch.

ETCS parameters:

- voltage on power rectifiers and brake resistors;

- power circuit current;

- voltage on the motor armature windings;

- housing fault voltage;

- power on rectifiers;

- brake pedal depress angle;

- wheel speed;

- speed of the dump truck movement;

- engine speed;

- field attenuation current;

- resistance of thermistors;

- emergency message codes;

- signal for switching on contactors;

- contactor feedback; 
- status of the travel and braking controller;

- speed limit signal status;

- status of the protection activation signal;

- state of the direction switch;

- state of the run-out mode generation signal;

- state of the independent excitation mode generation signal;

- field attenuation signal status;

- second position of the stroke controller;

- temperature of the bearings of the engines and the generator.

Hydraulic system parameters:

- emergency oil level in the hydraulic system tank;

- emergency oil temperature in the hydraulic system tank;

- emergency steering pressure;

- clogging of steering filters;

- emergency pressure in the front brake circuit;

- emergency pressure in the rear brake circuit;
- clogging of hydraulic oil filters;

- steering oil pressure;

- oil temperature in the hydraulic system;

- moving with a raised platform;

- driving with the parking brake on [4-8].

These parameters were summarized in a single table, in which the experts distributed the parameters in a decreasing order, depending on their importance. In addition, the experts showed whether there are systems to control these parameters at the enterprise. [29]

The method of expert assessments is one of the main ways to solve the problem of complex assessment of the impact of various parameters on the result. The expediency of using the method can be explained by the fact that it allows one to take into account the influence of a large number of different parameters, to develop a different view of the subject of research.

\begin{tabular}{|c|l|l|}
\hline The parameter & $\begin{array}{l}\text { Indicator of the importance of } \\
\text { the parameter for the } \\
\text { consumer }\end{array}$ & $\begin{array}{l}\text { The presence of a system } \\
\text { that controls the } \\
\text { parameter }\end{array}$ \\
\hline Name of the controlled parameter & $\begin{array}{l}\text { Please rate it on a scale from } \\
\text { "n" to "l" (the number of } \\
\text { parameters in the group) } \\
\text { Where, "n" is not important at } \\
\text { all } \\
\text { "l" is the most important }\end{array}$ & $\begin{array}{l}\text { Please indicate whether } \\
\text { this system is available to } \\
\text { consumers } \\
\text { " - yes }\end{array}$ \\
\hline 1 & 2 & " no \\
\hline General list of LFCS parameters (Loading and fuel control system): \\
\hline $\begin{array}{l}\text { 1. Dynamic weight of the transported } \\
\text { cargo; }\end{array}$ & \multicolumn{2}{|c|}{3} \\
\hline 2. Fuel level in the tank; &
\end{tabular}

Fig. 1. Questionnaire.

This questionnaire was sent to experts, provided by representatives of various companies and scientists. After receiving the completed questionnaires, all the information was processed and graphs were drawn up depending on the need for operation and the availability of the necessary equipment to meet this need. Thus, a certain schedule was built for each of the groups. 


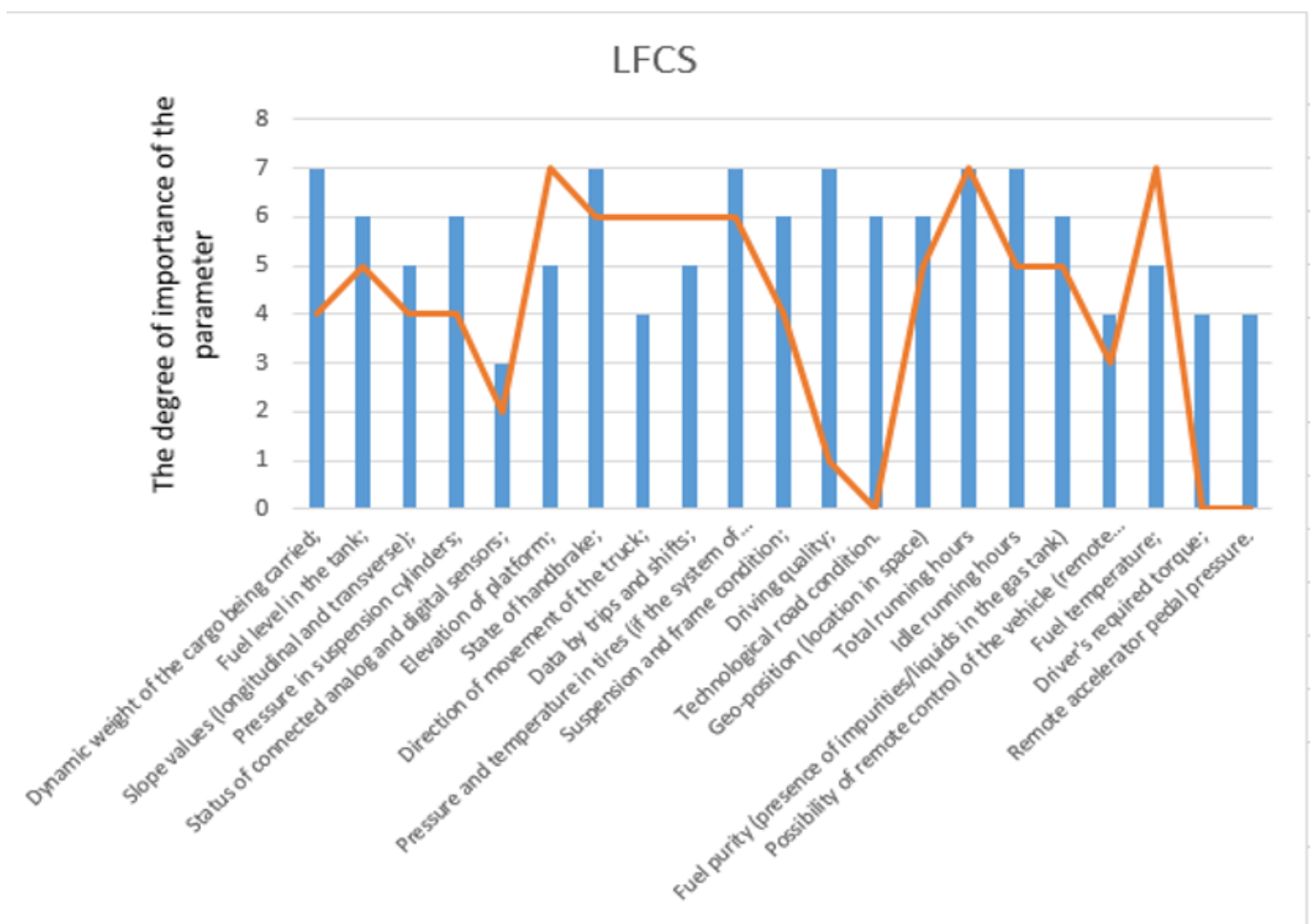

Fig. 2. Graph of LFCS parameters

The graph shows information, according to which it can be concluded that consumers highly value the parameters "Dynamic weight", "Driving quality" and "State of technological processes", but the curve shows that there are no sensors or systems that control these parameters for consumers. [30] Although all these factors are very important, for example, "Dynamic weight" shows whether there is an overload on the car, which in turn affects the wear of tires and hydraulic cylinders of the suspension, which leads to more frequent replacements of these elements, and, therefore, more spending on maintenance and repair. This causeand-effect relationship can be traced for each parameter. At first glance, it may seem that this is not so critical, but in fact, violating the rules of operation of various components and the car as a whole will lead to a decrease in the performance of not only a specific machine, but also the entire production as a whole. All the parameters that are not available to consumers, to one degree or another, affect the final efficiency of the production process.

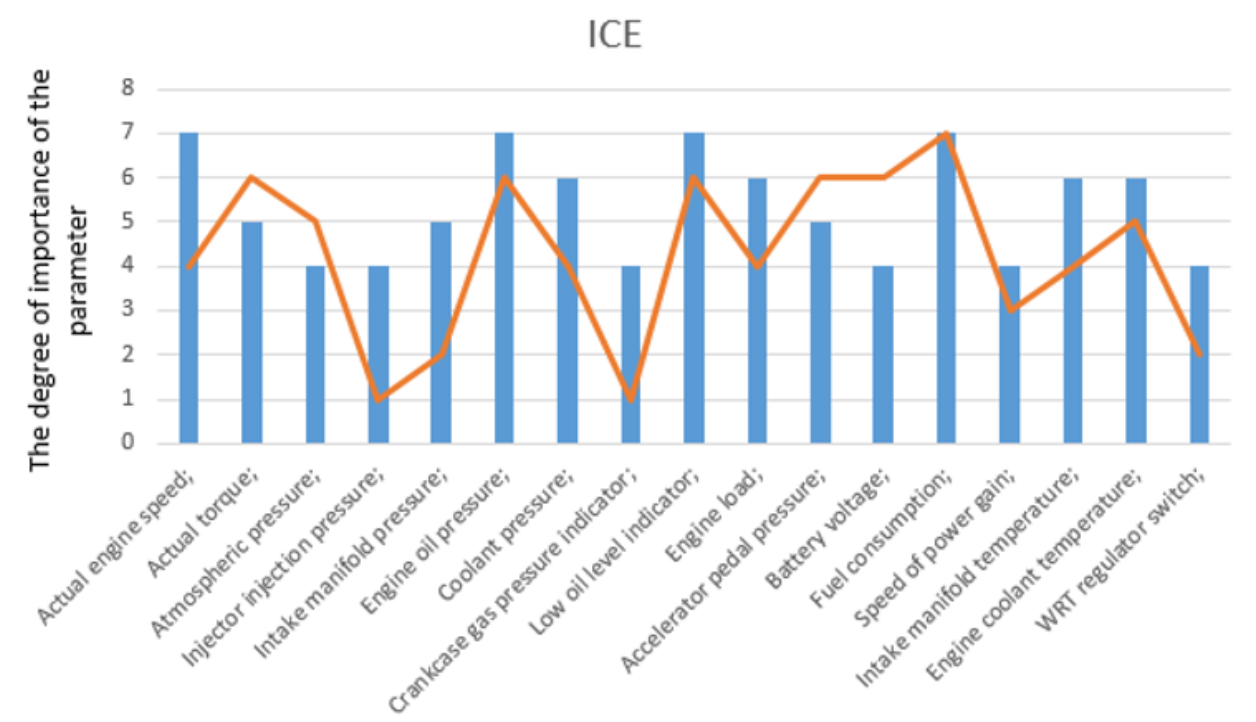

Fig. 3. Graph of ICE parameters

From the resulting graph, the following conclusions can be drawn: the supply for the systems of some parameters ("Battery Voltage" and "Accelerator Pedal Pressure") exceeds the need of consumers. It means that they believe that it does not make sense to install these systems, because they have little effect on the production process. At the same time, the need for such parameters as "Actual engine speed" and "Low oil level indicator" is higher than the ability of suppliers. 


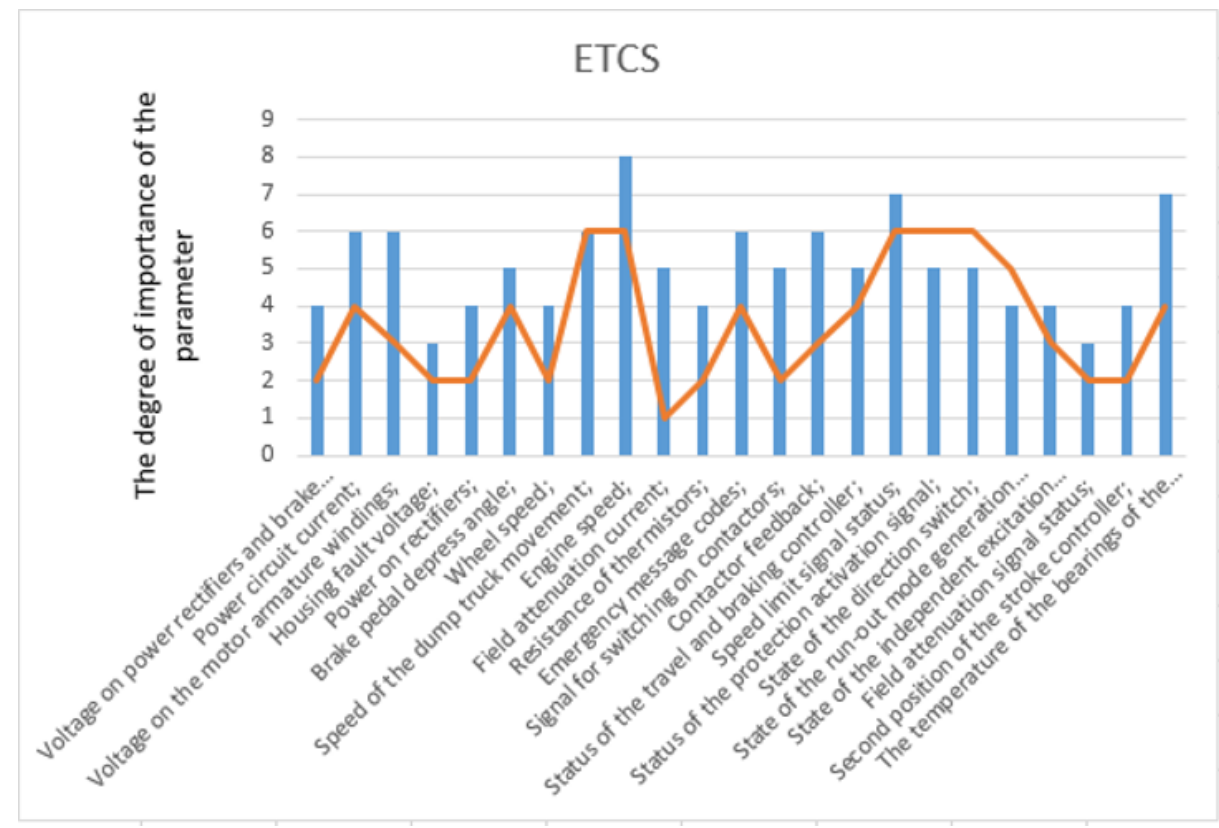

Fig. 4. Graph of ETCS parameters

The graph of the needs in the control system of traction electric drives shows that most of the parameters that consumers need are not provided by companies ("power circuit current", "bearing temperature of motors and generator" and "engine RPM"). It can be concluded, that it is necessary to establish communication and supply of equipment between the consumer and the manufacturer.

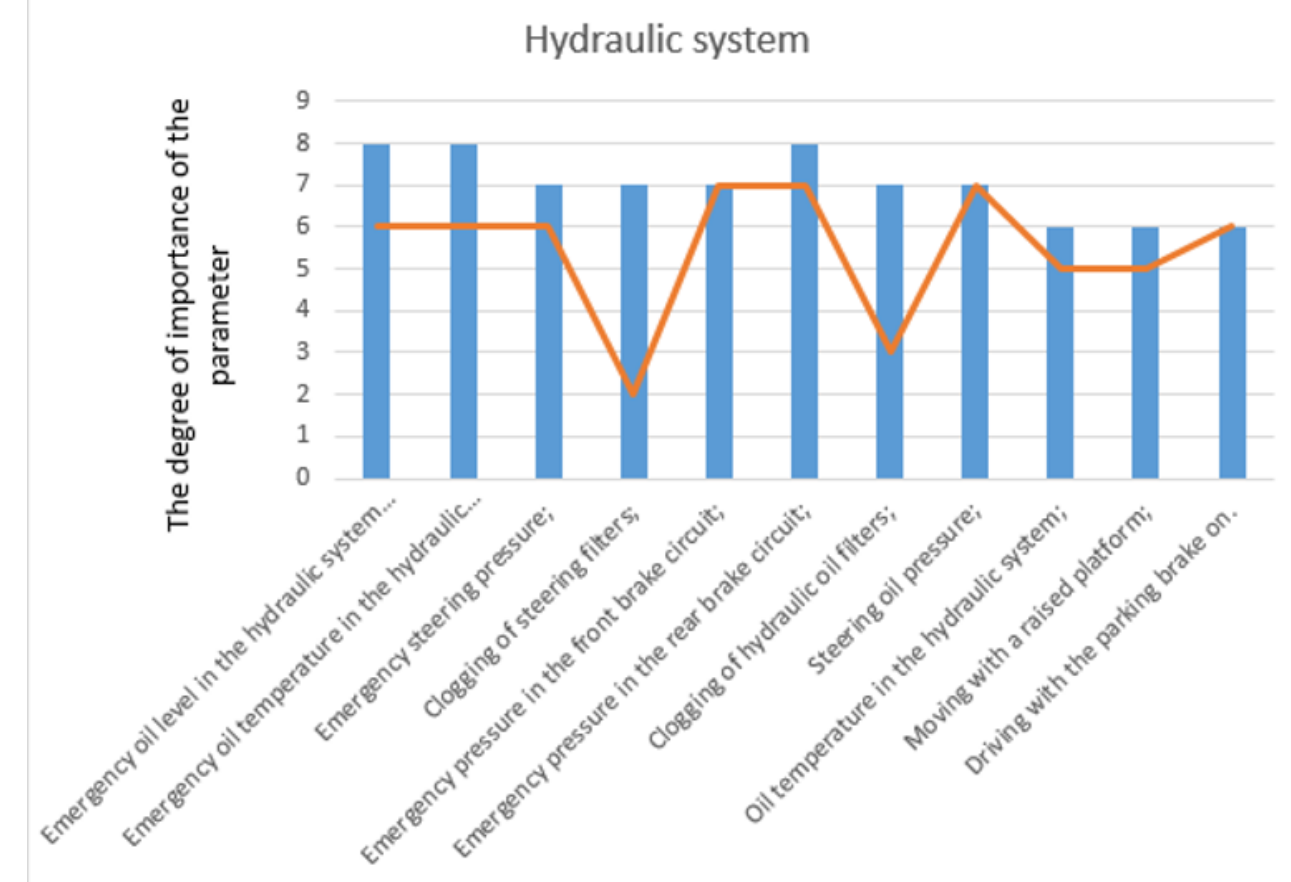

Fig. 5. Graph of hydraulic system

The hydraulic system contains the smallest number of controlled parameters, but even a lack of equipment for monitoring and timely maintenance can be observed ("clogging of hydraulic oil filters", "emergency oil temperature in the hydraulic tank" and "emergency steering pressure"). It should be noted again that all these parameters, brought to a critical point, can lead to serious and very expensive breakdowns. Breakdowns, in turn, will lead to the removal of a particular machine from the production process, which will negatively affect the efficient operation of the entire transport chain.

\section{Conclusion}

Summarizing all groups of parameters, according to the obtained schedules, it should be noted that for the successful and effective operation of the enterprise it is necessary to optimize the work of suppliers and develop a certain plan. It is necessary to create groups of different systems that will meet all the needs of production. For example, to make a set of provided equipment: 
- The "Maximum" package will provide control systems for all the parameters that the production needs. These parameters can be selected based on the graph data.

- The "Minimum" configuration will be based on a selection of the most important parameters, without which the operation of equipment is impossible in the modern world.

There can be many configurations, but as mentioned above, it is necessary to proceed from the calculation of the greatest financial benefit. In the end, it all comes down to the financial issue. Further study of automated control systems is a priority for the mining industry at the moment, as it is necessary to optimize the work to continuously improve efficiency and reduce the cost per ton of cargo transported [10-15].

\section{References}

1. R.N. Safiullin, A.S. Afanasyev, V.V. Reznichenko Proceedings of the Mining Institute, 237, (2019).

2. V.I. Alexandrov, M.A. Vasilieva, V.Yu. Koptev Zapiski Gornogo Institut., 239, (2019)

3. 3 V.A. Shpenst, Zapiski Gornogo Institut., 235, (2019)

4. I.O. Temkin, D.A. Klebanov, Mining information-analytical bulletin, 7, (2014).

5. A.E. Koziaruk, S.I. Taranov, A.V. Samolazov, Mining equipment and electromechanics, $\mathbf{1}$, (2014).

6. K.N. Trubetskoy, Mining Information and Analytical Bulletin, 4, (2013)

7. A.S. Abroskin, Proceedings of Tomsk Polytechnic University, 326 (12), (2015)

8. K.V. Belykh, D.A. Klebanov, Mining Industry, 2, (126), (2016)

9. K.N. Trubetskoy, M.V. Rylnikova, Gorny informatsionno-analiticheskiy bulletin, 8, (2015)

10. V.N. Machulov, Mining Industry 6, (111), (2013)

11. D.A. Klebanov, I.V. Kuznetsov, N.V. Bigel, Mining Industry, 4, (110), (2013)

12. A.F. Klebanov, D.N. Sizemov, M.V. Kadochnikov, Mining Industry, 2, (2020)

13. M. Koryagin, A. Voronov, Gorny informatsionno-analiticheskiy bulletin, 12, (2017)

14. P. Christopher, HSE Science News. Accessed at www.hse.ru/news/science/191202689.html

15. A.M. Turing, D. Hofstadter, D. Dennett, Computational Machines and the Mind, The Mind's Eye. (Samara, Bakhrakh-M, 2003)

16. V.Yu. Koptev, A.V. Kopteva, IOP Conference Series: Earth and Environmental Science, 2, 87, (2017)

17. M.A. Semenov, O.M. Bolshunova, A.A. Korzhev, IOP Conference Series: Earth and Environmental Science, 2, 87, (2017)

18. R.N. Safiullin, V.V. Reznichenko, R.R. Safiullin, Journal of Physics: Conference Series, 1, 1753, (2021)
19. P.K. Bakhaev, Journal of Physics: Conference Series, 5, 1333, (2019)

20. V.Y. Koptev, A.V. Kopteva, T.S. Ivanova, Journal of Applied Engineering Science, 1, 19, (2021)

21. D.I. Shishlyannikov, V.A. Romanov, I.E. Zvonarev, Journal of Mining Institute, 237, (2019)

22. A.S. Afanasyev, A.M. Egoshin, S.V. Alekseev, Journal of Physics: Conference Series, 1, 1753, (2021)

23. D.A. Shibanov, S.L. Ivanov, K.A. Safronchuk, IOP Conference Series: Materials Science and Engineering, 1, 966, (2020)

24. D.A. Shibanov, S.L. Ivanov, A.A. Yemelyanov, Journal of Physics: Conference Series, 10, 2020, (2020)

25. E.K. Abdulaev, P.N. Makharatkin, A.I. Shihov, Journal of Physics: Conference Series, 1, 1384, (2019)

26. E.K. Abdulaev, P.N. Makharatkin, E.V. Pumpur, IOP Conference Series: Earth and Environmental Science, 1, 378, (2019)

27. I.I. Beloglazov, P.A. Petrov, V.Yu. Bazhin, Eurasian Mining, 2, 2020, (2020)

28. N.V. Vasilieva, E.R. Fedorova, Tsvetnye Metally, 10, 2020, (2020)

29. E.K. Abdulaev, P.N. Makharatkin, A.I. Kuzhelev, IOP Conference Series: Materials Science and Engineering, 1, 775, (2020)

30. R. Safiullin, V. Fedotov, A. Marusin, Transportation Research Procedia, 50, (2020) 